\title{
Construção de estratégias de ensino com professores de Química: relatos de uma formação continuada
}

\author{
Construction of teaching strategies with Chemistry teachers: report of \\ continued training
}

\section{Construcción de estrategias de enseñanza con profesores de Química: informe de formación continua}

Jonathan Giovanella Laste ${ }^{1}$; Miriam Ines Marchi²; Patrick Alves Vizzotto3; Eniz Conceição Oliveira ${ }^{4}$; José Cláudio Del Pino ${ }^{5}$

\section{RESUMO}

Este trabalho consiste em uma análise das experiências vivenciadas ao longo de um Curso para Formação Continuada de Professores da área de Ciências da Natureza em uma Universidade Comunitária do Rio Grande do Sul. Com duração de sete encontros, o curso contou com cinco docentes de Ciências e Química do Ensino Fundamental e Médio, e abordou diferentes estratégias de ensino e formação pedagógica. A pesquisa apresenta caráter qualitativo, com características de estudo de caso. A produção de dados deu-se por meio de questionário, gravações das discussões dos encontros em áudio e trabalhos produzidos pelos participantes. As estratégias de ensino e as dificuldades vivenciadas por alunos e professores foram debatidas durante todos os encontros. Além disso, foi lançada a proposta de os professores desenvolverem um plano de unidade didática a partir das estratégias debatidas na formação. Como resultado, evidenciou-se um predomínio de metodologias ativas, visto que os professores instigaram os alunos para a criação de mapas conceituais, experiências com pilha de limão e elaboração de tabela periódica. Entre outros aspectos, tais estratégias privilegiam a autonomia dos alunos.

Palavras-chave: Formação de professores; Estratégias de ensino; Ciências e Química; Ensino Fundamental e Médio.

1 Graduado em Licenciatura em História pela UNIVATES, Lajeado/RS - Brasil. E-mail: jonathan.laste@universo.univates.br

${ }^{2}$ Doutorado em Química e professora titular da Universidade do Vale do Taquari - UNIVATES, Lajeado/RS Brasil. Atua, principalmente, nas seguintes linhas de pesquisa: Tecnologias, metodologias e recursos didáticos para o ensino e Formação de Professores e Práticas Pedagógicas no Ensino. E-mail: mimarchi@univates.br

${ }^{3}$ Doutorado em Educação em Ciências. Realiza estágio de Pós-doutorado (PNPD/CAPES) no Programa de Pósgraduação em Ensino da UNIVATES, pesquisando a temática da Alfabetização Científica. Participa dos Grupos de Pesquisa Processos de Ensino e Aprendizagem em Ciências - UNIVATES e Inovações no Ensino de Ciências - FURG. E-mail: patrick.fisica@hotmail.com

${ }^{4}$ Doutorado em Química e Pós-doutorado no Departamento de Educação e Psicologia da Universidade de Aveiro (UA) em Portugal. É professora titular da Universidade do Vale do Taquari - UNIVATES. Tem experiência na área de Ensino de Química, atuando principalmente nas seguintes linhas de pesquisa: Ciência, Sociedade e Ensino; Recursos, Tecnologias e Ferramentas no Ensino; Formação de Professores e Práticas Pedagógicas no Ensino de Ciências Exatas. E-mail: eniz@univates.br

${ }^{5}$ Doutorado em Engenharia de Biomassa e pós-doutorado pela Universidade de Aveiro-Portugal. Atualmente é professor associado da Universidade Federal do Rio Grande do Sul. Professor-Orientador do PPG Educação em Ciência Química da Vida e Saúde e do PPG Química ambos da Universidade Federal do Rio Grande do Sul. Bolsa de Produtividade em Pesquisa do Conselho Nacional de Desenvolvimento Científico e Tecnológico. Tem experiência acadêmica na área de Educação, com ênfase em Educação Química, atuando principalmente nos seguintes temas: formação de professores, ensino de química, material didático, currículo de química e informática educativa. E-mail: delpinojc@yahoo.com.br 


\section{ABSTRACT}

This work consists of an analysis of the experiences experienced throughout a Course for Continuing Education of Professors in Science at a Community University of Rio Grande do Sul. With seven meetings, the course had five teachers of Science and Chemistry of Elementary and High School, and addressed different strategies of teaching and pedagogical training. The research has a qualitative character, with characteristics of a case study. Data were collected through a questionnaire, recordings of discussions of audio meetings and works produced by the participants. The teaching strategies and difficulties experienced by students and teachers were discussed during all meetings. In addition, the proposal for teachers to develop a didactic unity plan was launched based on the strategies discussed in training. As a result, there was a predominance of active methodologies, since the teachers instigated the students to create conceptual maps, experiments with lemon stack and preparation of periodic table. Among other aspects, such strategies favor the autonomy of students.

Keywords: Teacher training; Teaching strategies; Science and Chemistry; Elementary and high school.

\section{RESUMEN}

Este trabajo consiste en un análisis de las experiencias experimentadas a lo largo de un Curso de Formación Continua de Profesores en el área de Ciencias de la Naturaleza. Con siete reuniones, el curso contó con cinco profesores de Ciencias y Química de Primaria y Secundaria, y abordó diferentes estrategias de enseñanza y formación pedagógica. La investigación tiene un carácter cualitativo, con características de un estudio de caso. Los datos se recopilaron a través de un cuestionario, grabaciones de debates de reuniones de audio y obras producidas por los participantes. Las estrategias de enseñanza y las dificultades experimentadas por los estudiantes y maestros se discutieron durante todas las reuniones. Además, se puso en marcha la propuesta de que los docentes elaboraran un plan de unidad didáctica basado en las estrategias debatidas en la formación. Como resultado, hubo un predominio de metodologías activas, ya que los profesores instigaron a los estudiantes a crear mapas conceptuales, experimentos con pila de limón y preparación de tabla periódica. Entre otros aspectos, tales estrategias favorecen la autonomía de los estudiantes.

Palabras clave: Formación del profesorado; Estrategias didácticas; Ciencia y Química; Primaria y secundaria.

\section{INTRODUÇÃO}

O debate em torno da formação de professores tem sido uma constante em ambientes acadêmicos e profissionalizantes. Segundo Tardif (2013), o ensino passa por uma evolução por vezes movida por continuidades, desvios, retrocessos e avanços ocasionais, variando absolutamente de um contexto para outro. Debate-se acerca da mercantilização da educação, da privatização da escola pública, da precariedade das instituições, do ofício, entre outras questões. Dessa forma, a necessidade por docentes preparados, que consigam articular teoria e prática de maneira funcional, dinâmica e lógica às particularidades dos estudantes, tem se manifestado como meta na formação de professores.

Se considerarmos que o fomento pela aprendizagem deve estar a par dos meios de condução e produção do conhecimento, discutir os caminhos para uma educação do futuro é abordar quem vivencia essa realidade diariamente. A partir dessa perspectiva, foi realizado, no ano de 2017, um curso de formação continuada de professores na área de Ciências da Natureza em uma Universidade Comunitária do Rio Grande do Sul, intitulado "Formação de professores em processos de ensino e aprendizagem em Ciência Química". Essa formação foi desenvolvida por meio do Projeto "Processos de Ensino e Aprendizagem em Ciências" desta Universidade, o qual é vinculado aos Programas de Pós-Graduação em Ensino da instituição.

O objetivo do curso, e nesse sentido, a justificativa do projeto, foi discutir metodologias que colaborem com o ensino e com a aprendizagem, contribuindo para uma melhor comunicação entre 
professores e estudantes. Priorizou-se, dessa forma, trazer diferentes estratégias de ensinagem (ANASTASIOU; ALVES, 2012), discuti-las entre o grupo e aplicá-las com os alunos. Esse roteiro deu ritmo aos encontros, mas ao mesmo tempo, insere-se dentro de um contexto por demandas direcionadas à formação continuada e ao estímulo a diferentes habilidades dos docentes. No total, sete encontros foram realizados com um grupo de professores, sendo em grande parte ocorridos no segundo semestre de 2017. Participaram, efetivamente, cinco professores do Ensino Fundamental e Médio.

Considerando o objetivo do curso buscou-se refletir sobre outras possibilidades de se organizar, estrutural e metodologicamente, a disciplina de Química no contexto da escola de nível médio, a partir da discussão e encaminhamento de diferentes estratégias de ensino, e neste artigo se pretende analisar uma série de diálogos e enunciações dos professores de Ciências e Química acerca das estratégias de ensino referidas ao longo do curso de formação.

Na sequência desta publicação, tem-se os referenciais teóricos selecionados, perpassando pelo ato de ensinar e aprender, a formação da cidadania, as habilidades para o Ensino de Ciências e os saberes profissionais dos professores. O processo metodológico da pesquisa é discutido em seguida, revelando o passo a passo da coleta de dados, da análise dos discursos e das enunciações dos participantes. Finalmente, são apresentadas as discussões que movimentaram os encontros e são analisados os métodos utilizados no desenvolvimento dos planos de unidade e sua aplicação na sala de aula.

\section{FUNDAMENTAÇÃO TEÓRICA}

Entre os objetivos do curso se busca estabelecer uma melhor relação entre estudantes e professores, portanto é condizente a apropriação do conceito de "ensinagem", discutido por Anastasiou e Alves (2012). Para os autores, a ensinagem é uma prática social complexa entre os sujeitos, na qual professor e aluno relacionam-se mutuamente no processo de ensinar e aprender, de forma contratual, "de parceria deliberada e consciente para o enfrentamento na construção do conhecimento escolar, decorrentes de ações efetivadas na sala de aula e fora dela" (ANASTASIOU; ALVES, 2012, p. 20).

Segundo Delizoicov e Angotti (1990), a falta de proximidade entre professor e aluno, no sentido de não estabelecer uma forte relação entre teoria e prática, ou desconsiderar as situações do meio social dos estudantes, é uma das maiores causas de desinteresse dos alunos. Considera-se que o amparo às necessidades dos estudantes deve ser construído a partir da relação entre os métodos científicos e a realidade social do aluno, tarefa impulsionadora na formação de cidadãos conscientes.

Freire (1996) nos diz que a formação da cidadania se centra, principalmente, no estímulo à tomada de decisão. A escola, como parte do mundo social, tem papel formador nessa perspectiva. É importante o professor oportunizar atividades que aproximem os estudantes de situações concretas, nas quais o poder de tomada de decisão reflita, mesmo que hipoteticamente, os efeitos e consequências da vida real. Delizoicov e Angotti (1990) apontam uma série de habilidades para o Ensino de Ciências que são responsáveis por preparar o aluno como cidadão: observação, classificação, registro e tomada de dados, construção de tabelas, análise de informações, síntese, aplicação.

Já em relação à formação de professores, Falsarella (2004) enxerga um processo ininterrupto, de não separação entre formação inicial e continuada. Para a autora, o imediatismo contemporâneo 
exige atualizações constantes na trajetória do docente. Nesse sentido, Nóvoa (1996) complementa que favorecer a reflexão crítica é o que há de fundamental. A formação necessariamente implica o repensar das práticas de sala de aula e a reconstrução contínua de uma identidade pessoal, dando dimensão ao saber da experiência.

Na obra "Saberes Docentes e Formação Profissional", Tardif (2018) apresenta ensaios escritos entre 1991 e 2002 (ano da publicação original), discutindo o ensino e o papel do professor. Nesse trabalho, o autor refere-se ao saber dos professores a partir de um conjunto de fios norteadores. 0 primeiro deles relaciona trabalho/ensino e sua aproximação com a sala de aula. Nessa perspectiva, o enfrentamento de problemas cotidianos é intrínseco ao ambiente de ensino, e é o próprio ato do docente mediar o trabalho que fornece os princípios para sua solução. Tardif (2018) também ressalta a diversidade do saber, ou seja, o conjunto de conhecimentos construídos além da formação, imprescindíveis à ação-docente e de um saber fazer plural e heterogêneo.

Outro fio condutor, o de temporalidade, reconhece que o conhecimento é um processo contínuo, adquirido ao longo da vida e da carreira profissional. Já a experiência de trabalho enquanto fundamento do saber destaca a importância dos saberes derivados da experiência de trabalho regular, fundamental ao desenvolvimento de competências profissionais. O quinto fio, saberes humanos a respeito de saberes humanos, diz respeito ao contato direto com o objeto de trabalho, estimulando uma noção de interação humana entre os indivíduos. Por fim, saberes e formação profissional, é a consequência das questões anteriores. É a reflexão, o repensar das práticas e saberes, a necessidade por renovação e aprendizagem.

Na mesma linha, torna-se importante a discussão sobre as experiências dos professores na elaboração de propostas didáticas de Química e a produção de estratégias de ensino que incluem a elaboração de materiais didáticos como processo de formação na prática docente. Maldaner (2000) menciona que a prática de muitos professores está comprometida com um currículo rígido, que favorece conteúdos desconectados entre si e fora da realidade dos alunos, situação que cria a desvalorização da aula como um local de construção e mudança, tanto dos alunos quanto dos próprios professores. Contrapondo esses professores, tem-se o professor-pesquisador, que procura na sua prática docente a formação de cidadãos críticos, buscando continuamente o seu aperfeiçoamento.

Para mudar o quadro apresentado por Maldaner (2000), ser professor-pesquisador é necessário, mas não o suficiente. O professor que pesquisa sua prática também deveria ter um espaço para discutir/legitimar os saberes por ele construídos. Esse espaço

[...] possibilitaria a reflexão e a interface dos saberes produzidos no âmbito da educação química, tanto nas universidades quanto nas salas de aula nas escolas de Ensino Básico. A partir da discussão de ideias e da exposição das experiências vividas pelos professores, é possível a construção de alternativas para implementar novas abordagens do conteúdo. Abordagens que tragam estímulo para buscar um aprofundamento dos temas, e uma diversificação das formas em que as aulas são trabalhadas (AUTOR-A 2009, p. 19).

Eichler et al. (1998) relatam que a produção de materiais didáticos de Química elaborados internamente na Área de Educação Química da Universidade Federal do Rio Grande do Sul (UFRGS), por bolsistas de iniciação científica e extensão, tem seu início nos anos 90. Esses materiais serviram para desencadear um processo contínuo de produção de materiais didáticos alternativos ao livro texto, por professores da Educação Básica. Naquele momento, os professores utilizavam temas geradores relacionados ao cotidiano de suas escolas. Por exemplo, com o tema gerador "água", foram 
elaboradas e aplicadas três unidades: Estrutura da água; Água da chuva e Tratamento da água. A divulgação do material produzido em encontros com professores da Educação Básica e sua utilização com alunos do curso de Licenciatura em Química e com professores nos cursos de Especialização e Extensão, da UFRGS, propiciou o maior envolvimento desses na proposição e confecção de outros materiais didáticos (EICHLER, AUTOR A, 2010).

Frison et al (2010, p. 441) apresentam a análise e reflexão durante a construção e desenvolvimento de uma proposta de inovação curricular para o ensino de Química, tendo como eixo norteador a Situação de Estudo (SE) - Pilhas e Baterias: efeitos para o ambiente e o ser humano. "A proposta metodológica na modalidade de SE inclui uma reorganização dos conteúdos de modo a integrá-los e inter-relacioná-los". Essa SE foi desenvolvida por uma estagiária do curso de Licenciatura em Química, em interação com professor de Química, que atua na Educação Básica e uma turma do $2^{\circ}$ Ano do Ensino Médio. A SE tinha como objetivo:

[...] investigar a possibilidade de desenvolver os conceitos químicos de forma intra e interdisciplinar, articulando conceitos cotidianos e científico-escolares e, ao mesmo tempo, produzir entendimento acerca dos danos que podem ser ocasionados pelo destino inadequado de resíduos sólidos, em especial pilhas e baterias, bem como as consequências que esses dispositivos podem acarretar ao ser humano e ao ambiente (FRISON et al, 2010, p. 443).

A partir do trabalho desenvolvido na SE e da análise da experiência vivenciada desde as primeiras aulas, os autores perceberam que, ao produzir uma proposta de ensino com base nos temas sociais relacionados a situações cotidianas, torna-se possível a contextualização dos conhecimentos que se deseja ensinar (EICHLER, AUTOR A, 2010).

Lima Filho et al. (2011) desenvolveram uma proposta com o objetivo de mostrar a importância da produção, pelo professor e alunos, de materiais didáticos alternativos, bem como, analisar o interesse, o desempenho e a aprendizagem significativa nas atividades e avaliações. Para a realização das atividades, foram selecionados os seguintes conteúdos:

[...] atomística, tabela periódica e propriedades periódicas, ligações químicas e geometria molecular no $1^{\circ}$ ano; cadeias carbônicas e funções orgânicas no 30 ano. Os materiais alternativos utilizados foram: isopor, bolinhas de isopor, varetas de madeira, cartolina, caixas de fósforo, pincéis, tintas guache ou de tecido, tachinhas, arames, alfinetes e bloquinhos de papel (LIMA FILHO et al., 2011, p. 171).

Os autores observaram que o professor teve facilidade de ensinar os conteúdos propostos, mesmo sendo abstratos. A análise do trabalho desenvolvido "mostrou que os alunos foram capazes de formular os seus próprios conceitos com relação às teorias explanadas em sala de aula. Isso refletiu a facilidade na resolução de problemas e no ótimo desempenho das avaliações" (LIMA FILHO et al., 2011, p. 172).

A partir do exposto, evidencia-se que ao assumir o papel de professor-pesquisador (professorinvestigador) o professor possibilita não somente a obtenção de melhores resultados nas práticas desenvolvidas com os alunos, mas também evidencia que a docência assume um novo interesse, uma nova motivação, gerando maior empenho e entusiasmo profissional. Esse contexto de autoformação tem como suporte o professor reflexivo, investigador de sua própria prática (CACHAPUZ et al., 2001). 


\section{METODOLOGIA}

O presente estudo, que segue uma abordagem qualitativa, consiste em um estudo de caso, uma vez que o método oportuniza problematização das discussões e da argumentação entre os envolvidos, privilegiando a interpretação em contextos específicos (YIN, 2015; LÜDKE; ANDRÉ, 2012). Os dados foram produzidos por meio da gravação dos encontros, seguido pela transcrição das falas. Os professores foram identificados numericamente ao longo do artigo. Também assinaram o Termo de Consentimento Livre e Esclarecido expressando sua conformidade em participar das atividades previstas no curso, e da coleta de informações para posterior utilização na pesquisa.

Sendo o objetivo da pesquisa analisar uma série de diálogos e enunciações dos professores de Ciências e Química acerca de estratégias de ensino ao longo do curso de formação, optou-se pela utilização da Análise Textual Discursiva como método de análise dos dados. De acordo com Moraes e Galiazzi (2011, p. 112), este método possibilita uma compreensão mais complexa dos discursos analisados, pois envolve um "[...] processo de desconstrução, seguido de construção, de um conjunto de materiais linguísticos e discursivos, produzindo-se a partir disso novos entendimentos sobre os fenômenos e discursos investigados".

Dessa forma, em um primeiro momento, organizaram-se quatro grandes unidades temáticas que abrangiam todos os encontros, um processo de desconstrução ou unitarização das informações das transcrições das falas dos professores. A partir dessas unidades, foi elaborada uma tabela (primeiro divididas por encontros e depois agrupando-os) para cada unidade temática, quais sejam: estratégias, dificuldades dos professores, tecnologias e dificuldades dos alunos. Finalizada essa parte, buscou-se identificar similaridades de conteúdo nas falas dos professores, gerando novas categorias dentro das unidades gerais. Assim como estas, as categorias foram organizadas em tabelas com temas específicos, como autonomia dos estudantes, interdisciplinaridades e organização escolar. Estes procedimentos objetivam categorizar as diversas unidades definidas na primeira etapa da análise dos resultados. A partir da finalização dessa etapa, foi possível a construção do metatexto, o qual expressou a soma de argumentos que permitem a compreensão dos fenômenos investigados (MORAES; GALIAZZI, 2011).

Contextualizando o processo dos encontros, os coordenadores do projeto escolheram o livro "Processos de ensinagem na universidade: pressupostos para as estratégias de trabalho em aula", (ANASTASIOU; ALVES, 2012), para ser utilizado como referência para as discussões, uma vez que esta bibliografia é utilizada rotineiramente em disciplinas dos Programas de Pós-Graduação em Ensino. Dessa forma, o grupo deveria ler um capítulo previamente selecionado para nortear a realização das atividades, que incluíam responder questionários sobre o ensinar e aprender Química, desenvolver a estratégia GV/GO (grupo de verbalização e de observação) e o desenvolvimento de um plano de unidade didática.

\section{OS RESULTADOS E DISCUSSÃO}

\subsection{DISCUSSÃO DOS ENCONTROS}

Um dos objetivos do curso de formação foi discutir a realidade profissional dos professores, objetivando repensar a proposta didática de sua disciplina, e assim abrir espaço para discutir seu papel profissional no contexto educacional de seu trabalho/de sua escola. Sendo assim, ao longo dos 
sete encontros, a realização de atividades e do plano de unidade didática foi intercalada por reflexões entre os participantes. Datas foram selecionadas especialmente para a troca de experiências e diálogo entre o grupo. A partir das conversas, foi possível classificar as discussões, que abrangiam, em sua maioria, dificuldades vivenciadas no dia a dia escolar. Questões relacionadas a políticas públicas e organizacionais foram o ponto de partida do debate.

O que parece um consenso entre os professores é que os problemas em torno da organização escolar são reflexos da aplicação (ou não) de políticas públicas. Deve-se considerar que o "desleixo" por parte do governo em transformar a realidade da escola pública no Brasil impacta na qualidade de ensino, uma vez que a própria coordenação pedagógica e o núcleo escolar como um todo acabam prejudicados pela falta de informação ou participação nas decisões "vindas de cima". Compreendese, a partir da fala dos participantes, que uma parte considerável dos problemas de organização são resultantes de uma relação de poder desigual, de uma escola sem voz, submissa às decisões governamentais.

Tal abordagem converge com as ideias de Tardif (2018). Para o autor, a desvalorização dos saberes dos professores pelas autoridades educacionais é uma constante na história da educação, devendo ser reconhecida e debatida como um problema político. Durante grande parte da História, a profissão foi associada a virtudes eclesiásticas, que variavam de obediência a vocação. A partir do século XX, como corpo estatal, a classe é submetida às decisões da autoridade pública. Sendo assim, Tardif (2018) sugere que os professores sempre estiveram subordinados a organizações maiores, mais fortes e poderosas que eles.

[...] na maioria dos países, no que se refere ao aspecto sociocultural, os professores se encontram, com muita frequência, em último lugar na longa sequência dos mecanismos de decisão e das estruturas de poder que regem a vida escolar. Em suma, seu poder, não somente na vida dos estabelecimentos escolares, mas na organização e no desenvolvimento de seu próprio trabalho, é realmente muito reduzido (TARDIF, 2018, p. 243).

Contudo, os docentes do grupo de formação não deixam de apontar as contradições internas da escola. As reuniões pedagógicas, por exemplo, não exercem o papel que deveriam. Segundo o Professor 3, "90\% (das reuniões) são recados, e os outros $10 \%$ é fazer plano de trabalho". O Professor 1 chama atenção para a má utilização do tempo, que acaba sendo reservado para questões burocráticas e pouco relacionadas com as aulas.

Outra reclamação refere-se à falta de integração entre as disciplinas. Para o Professor 1, o grande problema está na falta de aproximação entre as áreas, comprometida pela organização curricular: "[...] eu não consigo falar com o pessoal do Português, porque no momento em que o Português tem as reuniões deles, eu estou em sala de aula, no momento em que a História tem as reuniões deles, eu estou em sala de aula [...]" (Professor 1). Essa falta de sincronia entre as disciplinas traz consigo algumas consequências. Os professores acreditam que a própria busca por novas metodologias é prejudicada, uma vez que a escola segue uma visão conteudista de ensino: "aí tu vai atrás de alguma coisa (outras metodologias) aí vem aquela cobrança, tu não venceu (o conteúdo) [...] então assim, elas (a coordenação) cronometraram um tempo que a gente tem para trabalhar cada conteúdo" (Professor 2).

A prática docente de muitos professores atualmente está comprometida com um currículo rígido, que prestigia conteúdos desconectados entre si, e, sobretudo do cotidiano dos alunos, situação que 
desvaloriza a aula como um local de construção e mudança, tanto dos alunos quanto dos professores (STRACK, et al, 2009).

Conforme evidenciado, a crítica não deixa de se dirigir aos próprios colegas que, muitas vezes, não revelam comprometimento com as atividades escolares, não comparecendo em atividades que promovem a integração do grupo de professores. Essa falta de proximidade entre as disciplinas traz consequências diretas no ensino, dificultando, e muitas vezes impedindo, que propostas interdisciplinares ocorram. Nóvoa (1996), nesse aspecto, atenta para a perda na cultura profissional do docente. Segundo essa perspectiva, é na escola e no diálogo com os colegas professores que se aprende a profissão, ou seja, a reflexão sobre o trabalho é elemento central para o aperfeiçoamento e a inovação. Não obstante, o empenho em buscar novas metodologias também se vê prejudicado por questões relacionadas a essas, nesse caso, atribuído a atuação da coordenação, que acaba pressionando o vencimento do conteúdo. Com relação a este aspecto, Nóvoa (1996) reclama uma competência coletiva do núcleo escolar, uma vez que a complexidade do trabalho diário pede por um aprofundamento das equipes pedagógicas além das questões individuais. É a "necessidade de um tecido profissional enriquecido, de integração na cultura docente de um conjunto de modos coletivos de produção e regulação do trabalho escolar" (NÓVOA, 1996, p. 07).

Nesse sentido, tanto a escola quanto a universidade, muitas vezes, acabam criando ambientes hostis e segregadores, movidos por lutas de poder e prestígio, exclusões e ignorância recíprocas, em que reinam hierarquias simbólicas e materiais estéreis entre os professores dos diferentes níveis de ensino (TARDIF, 2018). Todavia, o autor ressalta que, se almejamos professores sujeitos do conhecimento, é preciso dar-Ihes espaço dentro do sistema escolar, para que possam agir como atores autônomos de seus métodos, sujeitos competentes de sua própria profissão.

Cachapuz et al. (2001) corroboram com tal abordagem, referindo que os professores estão no centro do processo. Para os referidos autores, é no diálogo com seus pares que os professores constroem suas identidades, numa perspectiva de professor-investigador. Os autores apontam, ainda, que ao associarem sua prática pedagógica à investigação, os professores obtêm melhores resultados com seus alunos. Além disso, a docência torna-se mais interessante e motivadora.

Este perfil de professor-pesquisador permite que sua prática docente atinja o objetivo de formação de cidadãos críticos na busca de sua educação científica. Este professor tem em sua sala de aula o seu objeto de estudo, buscando continuamente o aperfeiçoamento desta prática (STRACK, et al, 2009).

Os processos de ensinar e aprender foram questionados a partir das dificuldades enfrentadas pelos alunos. Na visão dos professores, grande parte dos alunos é muito dependente da escrita e da orientação do professor. A carência de métodos que possibilitam a autonomia do aluno foi perceptível a partir dos resultados das dinâmicas propostas pelos professores em seus planos de unidade didática. O professor 5 relata sua proposta de trabalho com seus alunos:

"Ensino a medir quem não aprendeu eu vou lá individual do a minha aula, porque daqui a pouco com a minha aula também ele não aprendeu nem a medir nem atingir o meu objetivo. [...] Faço retomada daquele conteúdo de maneira diferente, porque não adianta também eu usar aquelas estratégias que não vai chamar a atenção, de que maneira eu vou usar estratégia, fazer toda essa abordagem que esse aluno consiga aprender e isso hoje eu já passo sem sofrimentos, sem angustia." (Professor $5)$. 
Quando foi proposto que os alunos construíssem tabelas periódicas, o Professor 2 percebeu uma dificuldade primária na leitura de gráficos e legendas: "Se na tabela deles a massa atômica é no canto superior direito, para eles toda tabela é assim". Os conhecimentos químicos de maneira geral no ensino básico são tratados separadamente e, por essa razão, os alunos têm dificuldades de interpretação. Os trabalhos de Talanquer (2006) e Uehara (2005), que estudaram o tema reações químicas, confirmam o observado pelo Professor 2.

Outro problema percebido pelos professores se refere aos trabalhos copiados e operações mecânicas, ou seja, práticas que estimulam somente repetição e reprodução. Essas situações são frequentes no ensino com pesquisa, conforme referido pelo Professor 3: "Meus alunos não organizam a pesquisa em como pesquisar, e sim como fazer uma cópia daquilo que está lá e nem saber o que está escrito". O Professor 4 complementa: "Nem ler". Para o Professor 1, isso acaba desestimulando a correção das avaliações, uma vez que os trabalhos costumam ser quase iguais.

Uma questão que ronda o debate acerca da educação no Brasil refere-se ao papel da infraestrutura escolar como alicerce para uma aprendizagem qualificada. $O$ assunto veio à tona a partir da discussão sobre um objeto de aprendizagem de Química, o PensaQui, software interativo que tem como objetivo conhecer as concepções dos estudantes sobre a ocorrência de fenômenos físicos e químicos no seu cotidiano, e assim, possibilitar que os professores elaborem aulas que atendam às necessidades de cada grupo. Segundo o Professor 3, obstáculos referentes à infraestrutura são frequentes em escolas do interior, ou locais mais afastados dos grandes centros. Na escola onde leciona, por exemplo, a velocidade da internet oscila constantemente, impossibilitando, na maioria das vezes, atividades no laboratório de informática. O Professor 4, por sua vez, acrescenta que a falta de computadores para todos os alunos é outro ponto que compromete tais metodologias.

Segundo Soares Neto et al. (2013), tais dificuldade inserem-se em um grande conjunto de desigualdades regionais que o Brasil enfrenta. Ao analisar comparativamente a infraestrutura escolar por região e dependência administrativa, os autores concluíram que o Brasil ainda está longe de garantir um padrão mínimo de qualidade. Segundo o estudo, há um alto percentual de escolas que não possuem estruturas básicas, como sala de diretoria, sala de professores e biblioteca. A partir disso, os pesquisadores indicam que o combate às desigualdades deve, ao menos preliminarmente, estar pautado na promoção e fortalecimento das políticas públicas.

Ao longo dos encontros com o grupo de professores, algumas temáticas foram mais debatidas do que outras e, muitas vezes, o grupo retornava a problemáticas já debatidas. Isso se tornou pertinente à medida que ficava mais clara a relação dos professores com suas metodologias de sala de aula e suas perspectivas sobre o ensino e aprendizagem. Os professores relataram, dessa maneira, uma variedade de dificuldades e situações pedagógicas/profissionais, que serão abordadas na sequência.

\subsection{PLANOS DE UNIDADE DIDÁTICA}

A partir das discussões do grupo, nota-se que a falta de autonomia dos alunos é uma carência em termos metodológicos dos professores. Valendo-se dessa questão, as estratégias adotadas para a proposição didático-pedagógica dos professores desenvolverem um plano de unidade foram aquelas debatidas ao longo do curso. Esta se constituiu uma atividade centralizadora no pensar a organização curricular da disciplina de Química, em termos de conceitos fundamentais organizadores desta área de conhecimento, objetivo principal na realização do curso de formação dos professores. Como resultado, verificou-se um predomínio de metodologias que privilegiam a autonomia dos alunos, que 
consideram o estudante como sujeito na construção do próprio conhecimento. Nesses planos, os professores deveriam utilizar metodologias sugeridas no livro "Processos de Ensinagem na Universidade: pressupostos para estratégias de trabalho em sala de aula", organizado por Anastasiou e Alves (2010), e "Competências Pedagógicas do Professor Universitário", de Marcos Tarciso Masetto (2003), e aplicá-las em suas turmas de Ensino Fundamental ou Médio.

A seguir apresentaremos as produções dos professores quanto aos planos de unidade didática, considerando que os professores 3 e 5 participaram dos encontros, mas não realizaram tal atividade. Portanto, nos limitaremos a descrição e análise das propostas elaboradas e executadas em sala de aula pelos professores 1,2 e 4 .

O Professor 1, que trabalhou com uma turma de $2^{\circ}$ Ano do Ensino Médio, optou por estratégias que, primeiramente, favorecessem a introdução dos principais conceitos de eletroquímica. Na sequência, as habilidades dos estudantes acerca desse conteúdo foram estimuladas por meio de metodologias ativas. Considerando a abordagem de Berbel (2011), a escolha por métodos ativos pode contribuir para a autonomia do estudante quando fomenta a percepção do aluno sobre si mesmo, ao fazê-lo enxergar-se como origem da própria ação. Para tanto, o professor pode apresentar oportunidades de problematização de situações vividas no contexto escolar, seleção do conteúdo de estudo e alternativas inventivas nos possíveis caminhos que os levam ao desenvolvimento de respostas e soluções. Dessa forma, pensando uma forma criativa de abordar a eletroquímica, o Professor 1 impulsionou as habilidades dos estudantes a partir da construção de mapas conceituais e experimentação com pilha de limão, ele diz: "Eu sempre mostro pronto, e dou uma ideia mas imagino que fica interessante poder ensinar (a fazer o mapa) [...]" . O professor 2 informa "Eu fiz com densidade isso (ensinar a fazer o mapa)".

Retornando a questão do mapa, o Professor 3 relata que trabalha as duas metodologias discutidas, indicando que os livros de ciência do fundamental contribuem consideravelmente, uma vez que apresentam mapa no fim de cada capítulo. Quando pede aos alunos que façam seus mapas, o objetivo é utilizá-los para a construção de um texto posteriormente. Já o Professor 2 utiliza o mapa como uma estratégia para conhecer os conhecimentos prévios dos alunos, e testar suas compreensões do conteúdo:

\footnotetext{
"eu apliquei o mapa conceitual inicial para ver o que eles tinham de ideias prévias. A gente fez todo o trabalho expositivo, a gente...com software, tudo [...] aí eu pedi para eles reconstruírem o mapa para conseguir observar as diferenças, foi um trabalho bem legal assim, muito interessante. Eles têm que sintetizar as ideias, eles têm que fazer as conexões... Então se ele entendeu o conteúdo ele vai conseguir fazer, se não $[\ldots]^{\prime \prime}$ (Professor 2).
}

Segundo Anastasiou e Alves (2012), na construção de um mapa, é fundamental estabelecer e identificar as conexões entre os conceitos e seus derivados, criando uma forma de teia relacional. Quando os estudantes comparam os mapas construídos em grupo ou individualmente, entendem que as conexões podem ser diferentes, ampliando o quadro perceptível do grupo. Para o Professor 1, a funcionalidade dessa estratégia teve um contraste ainda mais positivo devido às experiências anteriores. O fato de deixar a construção a cargo dos alunos, ao contrário das outras vezes, quando já o trazia pronto, revelou-se pedagogicamente estimulante, uma vez que despertou outras formas de se aproximar do conteúdo, graças a diversidade atribuída aos mapas conceituais. Para Moreira (2013), tal diversidade é o que caracteriza seu poder como instrumento de aprendizagem, considerando que qualquer mapa deve ser encarado como uma possível representação de uma 
estrutura conceitual. Além disso, retomando os pressupostos fundamentais para a aprendizagem em Ciências de Delizoicov e Angotti (1990), considera-se que a metodologia utilizada pelo Professor 1 permitiu estimular habilidades de observação, classificação, registro e tomada de dados e análise de informações.

Outra estratégia utilizada pelo Professor 1 foi o esquema da Pilha de Daniell, com o qual foram introduzidos conceitos para serem trabalhados no experimento com a pilha de limão. Assim como a abordagem com o mapa, o professor modificou sua metodologia tradicional ao permitir que todos os alunos construíssem suas pilhas.

Os estudantes também ficaram incumbidos de montar um roteiro experimental, com análise dos procedimentos, materiais, atuação do ânodo e cátodo. Para o professor, a estratégia invertida trouxe o melhor resultado até então alcançado, relativamente a utilização de estratégias de ensino tradicionais, como a aula expositiva-dialogada. Isso pode ser explicado devido ao potencial que a metodologia tem de colocar o estudante como protagonista do processo de aprendizagem, sempre orientado pelo professor (BERGMANN; SAMS, 2012). Possibilitar o contato direto do estudante com o objeto de estudo, somado à realização do roteiro experimental, levou a um envolvimento consideravelmente superior aos realizados em anos anteriores.

Sendo assim, a utilização de diferentes estratégias de ensino pelo professor 1 foi fundamental, principalmente aquelas reportadas na formação continuada, possibilitando a elaboração de atividades experimentais alternativas ao livro didático, como relatado por Eichler e Autor AAutor AAutor A (2010).

Construção individual da tabela periódica, ensino com pesquisa e elaboração de jogos foram estratégias aplicadas pelo Professor 2, em uma turma de $9^{\circ}$ Ano do Ensino Fundamental. Assim como indicado pelo plano de unidade didática, as estratégias objetivaram a participação criativa dos alunos ao longo de todo o processo. A abordagem do professor buscou, primeiramente, associar os elementos químicos à rotina diária dos alunos. Para ele:

"os objetivos eram identificar a importância e a organização da tabela periódica, reconhecer a simbologia e nomenclatura dos principais elementos químicos, compreender a disposição dos elementos ao longo dos grupos e períodos, atribuir características gerais para os metais e não-metais, compreender as propriedades periódicas" (Professor 2).

O processo de familiarização dos estudantes com a tabela periódica se deu a partir da leitura de um texto sobre o histórico de sua organização. Cada aluno recebeu um grupo da tabela periódica para confeccionar um cartão $10 \mathrm{~cm}$ x $10 \mathrm{~cm}$ (deveria constar: simbologia, nome, número atômico e massa atômica). A construção se fez de maneira coletiva e o professor atuou como orientador geral, conforme o preceito de ensinagem (ANASTASIOU, ALVES, 2012). Além disso, os estudantes deveriam pesquisar as características gerais do grupo e as situações em que os principais elementos eram aplicados.

Na sequência, as propriedades periódicas foram abordadas a partir do ensino com pesquisa, e o trabalho final posteriormente socializado com os colegas. O último segmento do plano consistiu na elaboração de jogos (maioria de tabuleiro) a partir dos conhecimentos trazidos pelas metodologias anteriores. Segundo o relato do Professor 2, as estratégias funcionaram bem, tendo como principal característica o interesse dos estudantes em desenvolver seus próprios materiais. Para Bastos (2006), é típico das metodologias ativas despertarem a curiosidade do aluno, ao mesmo tempo em que 
oferecem meios para o desenvolvimento de habilidades específicas e soluções em conformidade com o perfil psicossocial da comunidade local.

A metodologia adotada pelo Professor 4 se distancia das anteriores pela falta de uma exposição/explicação inicial do conteúdo. Ao invés de fazer uma introdução dos conceitos gerais de reações químicas, o professor escolheu deixar todo o processo a cargo dos estudantes, que deveriam descobrir o que eram as reações químicas, selecionar e pesquisar uma em específico, apresentar para os colegas (realizando o experimento) e entregar um relatório. O professor relata "eu dei para eles um roteirinho, lá no início do ano ainda, e aí, a partir disso, eles procuraram os experimentos. Deixei eles bem livres, poderiam escolher o experimento que eles achassem legal". Para o professor, a liberdade dada aos alunos permitiu envolvimento e dinamicidade as aulas: "para mim introduzir as reações químicas não fui eu que fui lá e disse: "ó, funciona assim"! Eu pedi para eles procurar as reações, eles criarem o relatório, eles apresentarem para os colegas isso e explicar".

Os tipos de reações químicas foram tratados pelo professor somente após o término das apresentações e, para isso, se fez uso do software PhET, que permite simulações interativas em Matemática e Ciências. A proposta era que os estudantes utilizassem o software de maneira exploratória, priorizando o estudo de balanceamento das reações químicas. Para o professor, essa atividade trouxe os melhores resultados dentre as estratégias nomeadas no plano de unidade. Segundo ele, na avaliação que se seguiu sobre balanceamento das reações químicas, o resultado obtido foi o mais positivo até agora, efeito considerável dada complexidade do conteúdo e a constante dificuldade que os alunos costumam atribuir a ele.

Se percebe que as estratégias dos professores tiveram em comum o estímulo das habilidades dos estudantes. Considerando Bastos (2006), é papel das metodologias ativas dinamizar os processos de análise, pesquisas, estudos e decisões individuais ou coletivas, sempre objetivando soluções para um problema. É um fazer do conhecimento no qual a aprendizagem depende do próprio aluno. É possível visualizar esses pressupostos na construção da tabela periódica, no ensino com pesquisa, na criação de jogos interativos, nos relatórios experimentais. Ademais, cabe ao professor atuar como orientador no desenvolvimento das atividades, incitando a reflexão e a tomada de decisão do estudante.

Na mesma medida, os saberes docentes citados/indicados/propostos/definidos por Tardif (2018) nos ajudam a perceber uma série de desenvolturas profissionais, imprescindíveis ao êxito das metodologias. Se entendermos essas estratégias sob o ponto de vista do trabalho/ensino, compreende-se que os desafios atinentes às metodologias ativas são manifestações para um saber fazer plural, intrínsecos ao ambiente de ensino e necessários a diversidade do saber. Para Anastasiou e Alves (2012), o processo de ensinagem pode movimentar professor e estudante na construção do conhecimento escolar, devendo ser encarado de forma contratual, de parceria. É nesse aspecto que as metodologias desenvolvidas nos planos de unidades didática se beneficiam. Permitir a participação direta do estudante, seu contato com o objeto de estudo e o desenvolvimento de metodologias ativas, dinamizou os processos de ensinar e aprender química, estimulou a cidadania e a tomada de decisão, desenvolveu uma percepção heterogênea da ciência e fortaleceu a interação humana entre os indivíduos, ou seja, os saberes humanos (TARDIF, 2018). 


\section{CONSIDERAÇÕES FINAIS}

O Curso para Formação de Professores em Ciências realizado em uma Universidade Comunitária do Rio Grande do Sul, intitulado Formação de professores em processos de ensino e aprendizagem em Ciência e Química, abordou diferentes estratégias de ensino em turmas do Ensino Fundamental e Médio. Debateram-se metodologias diferenciadas daquelas tradicionais, e aspectos atinentes à formação dos professores, de uma forma que o curso contribuísse pedagogicamente com os processos de ensinar e aprender, além de possibilitar um melhoramento das relações entre professores e estudantes. Nesses encontros, os participantes manifestaram insatisfação pelas formas de organização escolar, no que compete ao poder público.

Nessa perspectiva, aborda-se em relações de poder, submissão escolar e o próprio histórico educacional brasileiro, que privilegia outras organizações, maiores, mais fortes e poderosas que a escola ou os professores. O que pode ser encarado como consequência dessa fragmentação do corpo docente - e que acaba atingindo o projeto educacional - são as divergências internas, movidas por lutas de poder e prestígio, formando um ambiente escolar excludente e segregacionista. É uma percepção quase pessimista da escola, mas que se enxerga como constante na história da educação no Brasil.

A análise dos planos de unidade didática revelou um desprendimento do ensino tradicional, na maioria das vezes pautado na aula expositiva. As estratégias sugeridas na literatura permitiram que os professores desenvolvessem seus planos de forma dinâmica e articulada. Os resultados demonstraram uma predominância de estratégias que privilegiam a relação direta entre os estudantes e o objeto de estudo.

A partir do que foi relatado pelos professores, se nota que a falta de autonomia dos alunos é debatida entre eles como a principal carência com relação as estratégias de ensino. A partir disso, não surpreende que todos os professores tenham adotado estratégias que valorizem o aluno como "sujeito" nos planos de unidade. As estratégias desenvolvidas tinham como ponto em comum o foco na prática, o contato direto do aluno com o objeto de estudo. Se percebeu uma desvinculação maior com a parte teórica, numa tentativa de trabalhar as percepções de cada aluno com o conteúdo, sem direcioná-lo a todo instante.

Nesse sentido, a construção de tabela periódica, o desenvolvimento conjunto de mapas conceituais, a organização de jogos interativos e as experiências químicas, estimularam habilidades de observação, classificação, construção de gráficos, análise de informações e aplicação, competências imprescindíveis ao ensino da ciência, além de despertar a curiosidade pelo conteúdo de formas mais atrativas e interativas, como aquelas ressaltadas na aplicação de metodologias ativas. Conclui-se que os estudantes se sentem mais envolvidos criativamente por estratégias dinâmicas e menos convencionais.

Como ficou evidente durante a discussão acerca da carência estrutural nas escolas do país, as políticas públicas devem cumprir um papel de fomentador do conhecimento e da educação. Para que diferentes estratégias de ensino sejam adotadas com eficácia, se faz necessário que as escolas tenham um mínimo de estrutura que suporte essas metodologias.

A educação brasileira tem revelado um grande conjunto de desigualdades regionais, problemas internos e particulares de cada escola, ou seja, uma realidade bastante distinta daquela desejada. 0 
devido comprometimento com as políticas públicas parece ser um primeiro passo para enfrentar essa série de empecilhos por uma educação de qualidade. O incentivo aos cursos de formação é outro lado dessa moeda. São processos graduais, de longo prazo, que não garantem uma superação absoluta das dificuldades, mas que desempenham um papel essencial para uma educação do futuro construída no presente.

\section{AGRADECIMENTOS}

Ao CNPq e a FAPERGS

\section{REFERÊNCIAS}

ANASTASIOU, Léa; ALVES, Leonir. Estratégias de ensinagem. In: (Orgs.). Processos de ensinagem na universidade. Pressupostos para as estratégias de trabalho em aula. 3. ed. Joinville: Univille, p. 67-100, 2012.

BASTOS, Celso. Metodologias ativas. 2006. Disponível em: http://educacaoemedicina.blogspot.com/2006/02/metodologias-ativas.html. Acesso em 17/09/2019.

BERBEL, Neusi. As metodologias ativas e a promoção da autonomia de estudantes. Semina: Ciências Sociais e Humanas, v. 32, n. 1, p. 25-40, 2011. Disponível em: http://www.uel.br/revistas/uel/index.php/seminasoc/article/view/10326. Acesso em 13/11/2019.

BERGMANN, Jonathan; SAMS, Aaron. Flip your classroom: Reach every student in every class every day. International Society for Technology in Education, 2012.

CACHAPUZ, António; PRAIA, João; GIL-PÉREZ, Daniel; CARRASCO, Jaime; MARTINEZ TERRADES, Isabel. A emergência da didáctica das ciências como campo específico de conhecimento. Revista Portuguesa de Educação, v. 14, n. 1, 2001. Disponível em: https://www.redalyc.org/pdf/374/37414108.pdf. Acesso em 13/11/2019

DELIZOICOV, Demétrio; ANGOTTI, José. Metodologia do ensino de ciências. São Paulo: Cortez, 1990.

EICHLER, Marcelo; BARBOSA, Valdeli; AUTOR A. Atividades integradas na produção de material instrucional em química. Extensão, v. 1, n. 1. 1998. Disponível em: https://www.lume.ufrgs.br/bitstream/handle/10183/89951/000230755.pdf?sequence=1. Acesso em $13 / 11 / 2019$

EICHLER, Marcelo; AUTOR A. A produção de material didático como estratégia de formação permanente de professores de ciências. Revista Eletrónica de Enseñanza de las Ciencias, v. 9, n. 3, 2010.

FALSARELLA, Ana. Formação continuada e prática de sala de aula. Autores Associados, 2004.

FREIRE, Paulo. Pedagogia da autonomia: saberes necessários à prática educativa. 18. ed. São Paulo: Paz e Terra, 1996.

FRISON, Marli; AUTOR A; CERETTA, Jaqueline. Algumas questões ambientais permeando a construção de propostas de inovação curricular para o ensino de Química. REMEA-Revista Eletrônica do Mestrado em Educação Ambiental, v. 23, 2009. Disponível em: https://periodicos.furg.br/remea/article/view/4570. Acesso em 13/11/2019 
MORAES, Roque; GALIAZZI, Maria. Análise textual discursiva. Ijuí: Editora Unijuí, 2011.

LIMA FILHO, Francisco; DA CUNHA, Francisca; CARVALHO, Flávio; SOARES, Maria. A importância do uso de recursos didáticos alternativos no ensino de química: uma abordagem sobre novas tecnologias. Enciclopédia Biosfera, Centro Científico Conhecer, Goiânia, v. 7, n. 12, 2011. Disponível em: http://www.conhecer.org.br/enciclop/conbras1/a\%20importancia.pdf. Acesso em $13 / 11 / 2019$.

LÜDKE, Menga; ANDRÉ, Marli. Pesquisa em educação: abordagens qualitativas. São Paulo: E.P.U., 2012.

MASETTO, Marcos. Competência Pedagógica do Professor Universitário. São Paulo: Summus, 2003.

MALDANER, Otávio. A formação inicial e continuada de professores de Química. Ijuí: Ed. Unijuí, 2000.

MOREIRA, Marco. O mapa conceitual como instrumento de avaliação da aprendizagem. Educação e Seleção, $\quad$ n. 10, $\quad$ p. 17-34, $2013 . \quad$ Disponível em: http://publicacoes.fcc.org.br/ojs/index.php/edusel/article/viewFile/2568/2521. Acesso em $13 / 11 / 2019$.

NETO, Joaquim; DE JESUS, Girlene; KARINO, Camila; DE ANDRADE, Dalton. Uma escala para medir a infraestrutura escolar. Estudos em Avaliação Educacional, v. 24, n. 54, p. 78-99, 2013. Disponível em: http://publicacoes.fcc.org.br/ojs/index.php/eae/ar ticle/view/1903. Acesso em $13 / 11 / 2019$.

NÓVOA, António. Formação de Professores e Profissão Docente. 1996. Disponível em: http://repositorio.ul.pt/bitstream/10451/4758/1/FPPD_A_Novoa.pdf. Acesso em: 04/09/2019.

STRACK, Ricardo; MARQUES, Magdalena; AUTOR A. Por um outro percurso da construção do saber em educação química. Química Nova na Escola, v. 31, n. 1, p. 18-22, 2009. Disponível em: http://qnesc.sbq.org.br/online/qnesc37_especial_2/06-EA-111-15.pdf. Acesso em 13/11/2019.

TALANQUER, Vicente. Commonsense chemistry: A model for understanding students' alternative conceptions. Journal of Chemical Education, v. 83, n. 5, p. 811, 2006. Disponível em: https://pubs.acs.org/doi/abs/10.1021/ed083p811. Acesso em 13/11/2019.

TARDIF, Maurice. A profissionalização do ensino passados trinta anos: dois passos para a frente, três para trás. Educação \& Sociedade, v. 34, n. 123, p. 551-571, 2013. Disponível em: https://www.redalyc.org/pdf/873/87328002015.pdf. Acesso em 13/11/2019.

TARDIF, Maurice. Saberes docentes e formação profissional. 17. ed. Petrópolis: Vozes, 2018.

UEHARA, Fabia. Refletindo dificuldades de aprendizagem em alunos do ensino médio no estudo do equilíbrio químico. 2005. 100 f. Dissertação (Mestrado em Ensino de Ciências Naturais e Matemática) - Universidade Federal do Rio Grande do Norte, Natal, 2005. Disponível em: https://repositorio.ufrn.br/jspui/handle/123456789/16122. Acesso em 13/11/2019.

YIN, Robert. Estudo de caso: planejamento e métodos. 2. ed. Porto Alegre: Bookman, 2015. 